\title{
Challenges in lower urinary tract and pelvic floor disorders: Where do we go from here?
}

\author{
Sender Herschorn, MD, FRCSC \\ Professor, Division of Urology, University of Toronto, and Head of Urodynamics Laboratory, Sunnybrook Health Sciences Centre, Toronto, ON
}

Cite as: Can Urol Assoc J 2013;7(9-10):S208. hittp://dx.doi.org/10.5489/cuaj.1629

Published online October 9, 2013.

$\mathrm{T}$ he proceedings of the 2013 Canadian Urology Forum clearly demonstrated that there are many outstanding challenges in the management of lower urinary tract and pelvic floor disorders. Although the faculty and participants did not develop any groundbreaking solutions to these challenges, the forum's educational sessions did clearly identify them and highlight the areas that will continue to require research and development of new therapeutic approaches in the future.

\section{Overactive bladder}

For overactive bladder $(\mathrm{OAB})$, medical science has come a long way in elucidating the cause(s) of this condition, but much research remains to be done. As discussed during the forum sessions, there are many new mechanistic avenues under study for the treatment of OAB. It is hoped that the study of these novel approaches will lead to further clarification of the etiology of this complex condition, perhaps to a modification of the definition of $O A B$ and to improved outcomes for our patients.

\section{Special populations}

The overviews of multiple sclerosis and the frail elderly not only focused on particular concerns and considerations in these patient groups, but also served as a reminder about the heterogeneity of these patient populations and the need to individualize therapeutic approaches on a patient-by-patient basis.

\section{Post-prostatectomy incontinence}

While the discussions highlighted that surgical interventions for post-prostatectomy incontinence can be effective, it was clear that there needs to be a greater degree of scientific scrutiny with respect to the evaluation and management of these patients. The existing evidence is lower-level; higher quality studies are required to make definitive recommendations.

\section{Urogynecology}

For patients with prolapse and concomitant voiding problems, although there was some degree of agreement about optimal approaches, there are no clear, evidence-based answers directing the best course of therapy. For women with sexual dysfunction and pelvic floor disorders, there was agreement that there is a need to identify and address sexual concerns in this population since many patients can experience substantial improvements, particularly with respect to coital incontinence.

\section{Bladder pain syndrome}

During this segment of the proceedings, it became clear that physiotherapy is an intervention that may help a large number of patients, but that this modality is greatly underutilized, in part due to lack of access. There was a lack of consensus with respect to the utility of other interventions, as the evidence is weak for many of the approaches that are mentioned in the current clinical practice recommendations.

\section{Conclusions}

While the discussion and deliberations among the faculty and participants at the 2013 Urology Forum provided important information regarding the evaluation and treatment of several difficult-to-treat populations, they also revealed substantial gaps in the literature and in our current understanding of disease pathophysiology and treatment. Our field is certainly one that must continue to evolve and refine current methods of delivering care to these diverse patient populations, and continue to search for answers. We hope to provide more questions and answers at the 2014 Urology Forum.

Competing interests: This article is part of a CUAJ supplement sponsored by Astellas Pharma Canada, Inc. Dr. Herschorn is an ongoing paid consultant for, or has received speaker fees, educational grants, and/or travel assistance from Allergan, American Medical Systems, Astellas, Merus Labs, Pfizer, and Promedon.

Correspondence: Dr. Sender Herschorn, Division of Urology, University of Toronto, Sunnybrook Health Sciences Centre, Rm. A309, 2075 Bayview Ave., Toronto ON M4N 3M5; s.herschorn@utoronto.ca 